\title{
Virtual issue: cell wall functions in plant growth and environmental responses
}

\author{
Hiroaki Iwai ${ }^{1}$ \\ Published online: 6 October 2021 \\ (c) The Botanical Society of Japan 2021
}

\begin{abstract}
Plant cell walls have multiple functions, including determining cell shape and size, cell-cell adhesion, controlling cell differentiation and growth, and promoting abiotic and biotic stress tolerance. This virtual issue introduces the physiological functions of cell walls in growth and environmental responses. The articles detail research on (1) embryogenesis and seed development, (2) vegetative growth, (3) reproductive growth, and (4) environmental responses. These articles, published in the Journal of Plant Research, will provide valuable information for future research on the function and dynamics of cell walls at various growth stages, and in response to environmental factors.
\end{abstract}

Cell wall components make various contributions to plant growth (Somerville et al. 2004). Various cell wall components have been detected in different plant organs, such as roots, leaves, stems, and flowers. Plant cell walls are dynamic structures composed of three main polysaccharide types: cellulose, hemicellulose, and pectin (Gigli-Bisceglia et al. 2019). These polysaccharides interact with structural proteins inserted in the cell wall matrix by various chemical bonds and physical arrangements to form a network (Caffall and Mohnen 2005; Cosgrove 2005; Scheller and Ulvskov 2010). These structures allow plant cells to maintain a defined shape, provide mechanical support, and maintain cell-to-cell communication in various organs. The composition and chemical structure of these polysaccharides change during plant growth in response to environmental and endogenous signals. The cell wall composition varies among species and cell types, and even by intracellular domains within the cell wall of a single cell (Yokoyama and Nishitani 2004). This variation in cell wall composition suggests that the plant cell wall is highly dynamic and regulated in a very specific manner (Carpita et al. 1993). The cell wall plays an important role in plant morphogenesis and environmental

The virtual issue is available at https://www.springer.com/10265.

Hiroaki Iwai

iwai.hiroaki.gb@u.tsukuba.ac.jp

1 Faculty of Life and Environmental Sciences, University of Tsukuba, Tsukuba, Ibaraki 305-8572, Japan responses (Bethke et al. 2016; Bidhendi and Geitmann 2016; Le Gall et al. 2015).

In this virtual issue, we list 16 recent papers published in the Journal of Plant Research that have contributed to our understanding of cell wall functions. These include papers on (1) embryogenesis and seed development, (2) vegetative growth, (3) reproductive growth, and (4) environmental responses.

\section{Embryogenesis and seed development}

In the tomato (Solanum lycopersicum L.), cell proliferation and rapid cell expansion occur in the ovary and embryo during early fruit development after pollination and early fruit formation. Terao et al. (2013) revealed changes in the distribution of cell wall polysaccharides, especially pectic galactans and arabinans, in ovules and fruit during early fruit development, via immunolocalization analyses using monoclonal antibodies specific for various cell wall epitopes. Du et al. (2020) also observed embryogenesis and dynamic changes in cell wall components of the Chinese chestnut (Castanea mollissima Blume) 'Huaihuang'. Their results also suggested rapid metabolism of pectin and the presence of hemicellulose (galactan, arabinan, and xylan) during embryogenesis. The distributions of cell walls during embryogenesis and reproduction have been observed not only in angiosperms but also in mosses. Henry et al. (2020) localized cell wall components in liverwort (Marchantia polymorpha L.) placental cells. Dynamic changes in cell 
wall components have been implicated in embryonic developmental processes. During seed development, a unique cell wall protein, seed and root hair protective protein (SRPP), has been reported. (Tanaka et al. 2014). The SRPP gene (At4G02270) is significantly induced in root hairs under phosphate deficiency. Using an SRPP mutant, Uno et al. (2019) focused on the relationship between SRPP and seed viability; loss of SRPP function results in small, shriveled seeds with low germination rates. The absence of SRPPs in the cell wall may trigger the defects in cell wall structure seen in the seed coat. These results suggest that SRPP is important for normal development of seeds.

\section{Vegetative growth}

The ability of plants to grow upright and penetrate the soil comes from the mechanical strength of the organism, which is provided by the solidification of semi-rigid cell walls. The cell wall also gives the plant the strength and plasticity it needs to withstand adverse environmental conditions. The primary cell wall is produced during cell division and expansion. and determines the shape and volume of the cell. After cell expansion, some plant cells produce lignified walls, called secondary cell walls, which support plant growth. Fernandes et al. (2016) determined the response of cell walls, specifically the rearrangement of components, to depletion of key individual nutrients using grape shoot internodes as an experimental model. Honta et al. (2018) showed that arabinan and UDP-arabinopyranose mutase (UAM) are involved in pectin side chains and arabinoxyloglucan, especially in vegetative development, using RNA interferenceinduced tobacco transformants. UAMs are required for the biosynthesis of arabinose side chains in both pectin and arabinoxyloglucan in Solanaceae, and the arabinan-mediated cell wall network is important for normal leaf development in tobacco. The arabinan-mediated cell wall synthesis and network affected normal cell differentiation during the development of various organs (Kotake et al. 2016). Saelim et al. (2018) analyzed AP2/EREBP genes in Group IIId Arabidopsis thaliana (L.) Heynh.. These genes are homologs of rice $E R F$ genes previously proposed to be associated with secondary cell wall biosynthesis. However, they are involved in the transcriptional regulation of the primary cell walltype CESA gene in Arabidopsis thaliana. Xylogenesis, the process of woody tissue formation, is accompanied by qualitative and quantitative cell wall changes. Shinohara et al. (2015) used cell wall-directed monoclonal antibodies from a Zinnia elegans Jacq. xylogenic culture system to identify two molecular events during xylogenesis. Stem mechanical strength is an important quantitative trait in agriculture closely related to host resistance in rice, which is reduced when fertilizers with high nitrogen contents are applied.
Secondary cell wall thickness is mainly responsible for stem strength (Aohara et al. 2009). Zhang et al. (2017) focused on nitrogen-induced gene regulation and demonstrated that nitrogen fertilizer affects stem mechanical strength by altering secondary cell wall synthesis in culm tissue. It was also reported that the cell wall thickened under Si-deficient conditions. Rice (Oryza sativa $\mathrm{L}$.) is a typical $\mathrm{Si}$-accumulating plant, in which more than $10 \%$ of the shoot dry weight may be accumulated $\mathrm{Si}$. Under Si-deficient conditions, rice is sensitive to several stresses. The expression of genes involved in secondary cell wall synthesis was increased to compensate for the reduced stress tolerance, and the contents of cellulose and lignin increased (Yamamoto et al. 2012).

\section{Reproductive growth}

Plant reproduction requires active communication between cells and changes in the cell wall, which also play an important role in pollen development. The tapetum plays an important role in anther development by providing material for pollen wall formation and nutrients for pollen formation.

Takebe et al. (2020) reported the properties of a malesterile glycine-rich protein 2 (OsGRP2) mutant, which was found to have irregular cell division and reduced tapetum function. GRP is a structural protein found in the cell walls of diverse plants. This paper revealed that OsGRP2 plays an important role in tapetum differentiation and function. Reproductive tissues are particularly rich in pectin compared to other tissues and play an important role in various developmental processes. The degree of methylesterification of pectin is an important determinant of its adhesive properties. After pollination, the pollen tube entering the stigma extends through the adhesive cells of the transmitting pistil tissue toward the ovary. In higher plants, the transmitting tissues along the pollen pathway contain large amounts of pectin (Iwai et al. 2006). In addition, the growing pollen tube actively synthesizes a pectin-rich cell wall at its tip. In pectin methyltransferase mutants, the level of pectin methylesterification in the cell wall of the transmitting pistil tissue is reduced, resulting in abnormal cell wall properties and the inability of pollen tubes to advance through the pistil transmitting tissue (Hasegawa et al. 2021). Maintaining the cell wall properties of the pistil transmitting tissue by pectin methylesterification may regulate the mechanical guidance of pollen tubes. The degradation of cell wall polysaccharides by various cell wall hydrolases during fruit softening causes structural changes in hemicellulose and pectin, which affect fruit physical properties and softening. Changes in cell wall degradation and cell wall polysaccharide biosynthesis and cross-linking, which are involved in fruit softening and fruit shape maintenance during ripening, vary among fruit tissues in tomato (Takizawa et al. 2014). The extent of cell wall 
modification, and the modifying enzymes activated during fruit softening, vary among fruit types. Expansins are proteins involved in the modification of plant cell walls, including cell expansion. Expansins also play an important role in fruit ripening by loosening the cell wall, making it more accessible to other cell wall-related enzymes. Expansins have been proposed to induce cell wall disassembly by breaking the non-covalent bonds between cellulose and matrix polysaccharides (Cosgrove 2000). Using strawberry fruit, Nardi et al. (2013) showed that expansins bind not only cellulose, but also to a wide range of cell wall polymers. After fruit development following pollination, the abscission zone of the pedicel strengthens its adhesion to keep the fruit attached. Non-pollinated flowers drop off at each abscission zone, but the same tissue expansion is observed in pollinated flowers. As the fruit grows and ripens, it readily sheds at the abscission zone, indicating that shedding is accelerated. Cell wall degradation and synthesis play important roles in these processes (Tsuchiya et al. 2015). Iwai et al. (2013) showed that different mechanisms regulate floral shedding, which is determined by successful pollination, and fruit shedding, which occurs after ripening, i.e., remodeling of cell wall polysaccharides and lignification, respectively.

\section{Environmental responses}

Various stresses affect plant growth, including pathogen attack, insect herbivory, high salinity, drought, and excessive temperature. Most plant cells are attached to neighboring cells through a common interface, the cell wall, and maintain their position during development. Since plant development depends on harmonious cell division, expansion, and differentiation, it is essential that individual cells are in harmony with developing neighboring cells in terms of adhesion and separation. Plant-parasitic nematodes parasitize many rhizomatous plants and take up nutrients, resulting in severe growth disorders in the host plant. During infection, root hump nematodes induce the formation of characteristic hyperplastic structures, called root humps or galls, in the roots of host plants. Ishida et al. (2020) showed that plantparasitic nematodes modulate host developmental mechanisms to reduce secondary cell walls and establish feeding sites.

Various mechanisms are involved in the detoxification of heavy metals in plant cells. Most of the heavy metals taken up by plants accumulate in the roots. Inoue et al. (2012) clarified the properties of lead deposited in the cell walls of radish roots grown in a glass bead bed containing lead pellets; they showed that the root cell wall has high affinity for $\mathrm{Pb}^{2+}$ and that the carboxyl groups of pectin play a role in $\mathrm{Pb}$ binding. Aluminum toxicity is another major cause of poor crop growth, especially in areas with acidic soils. Pectin in the cell wall also functions in aluminum toxicity and plays an important role as a barrier to prevent aluminum from entering rice (Nagayama et al. 2019).

I hope that these 16 articles provide valuable information for future research on cell wall function in plant growth and environmental responses.

\section{References}

Aohara T, Kotake T, Kaneko Y, Takatsuji H, Tsumuraya Y, Kawasaki S (2009) Rice BRITTLE CULM 5 (BRITTLE NODE) is involved in secondary cell wall formation in the sclerenchyma tissue of nodes. Plant Cell Physiol 50:1886-1897

Bethke G, Thao A, Xiong G, Li B, Soltis NE, Hatsugai N, Hillmer RA, Katagiri F, Kliebenstein DJ, Pauly M,Glazebrook J (2016) Pectin biosynthesis is critical for cell wall integrity and immunity in arabidopsis thaliana. Plant Cell 28(2):537-556. https://doi.org/ $10.1105 /$ tpc. 15.00404

Bidhendi AJ, Geitmann A (2016) Relating the mechanics of the primary plant cell wall to morphogenesis. J Exp Bot 67(2):449-461. https://doi.org/10.1093/jxb/erv535

Caffall KH, Mohnen D (2009) The structure, function, and biosynthesis of plant cell wall pectic polysaccharides. Carbohydr Res 344(14):1879-1900. https://doi.org/10.1016/j.carres.2009.05.021

Carpita NC, Gibeaut DM (1993) Structural models of primary cell walls in flowering plants: consistency of molecular structure with the physical properties of the walls during growth. Plant J 3(1):1-30. https://doi.org/10.1111/j.1365-313x.1993.tb00007.x

Cosgrove DJ (2000) Loosening of plant cell walls by expansins. Nature 407(6802):321-366. https://doi.org/10.1038/35030000

Cosgrove DJ (2005) Growth of the plant cell wall. Nat Rev Mol Cell Biol 6(11):850-861. https://doi.org/10.1038/nrm1746

Du B, Zhang Q, Cao Q, Xing Y, Qin L, Fang K (2020) Changes of cell wall components during embryogenesis of Castanea mollissima. J Plant Res 133:257-270

Fernandes JC, Goulao LF, Amâncio S (2016) Immunolocalization of cell wall polymers in grapevine (Vitis vinifera) internodes under nitrogen, phosphorus or sulfur deficiency. J Plant Res 129:1151-1163

Gigli-Bisceglia N, Engelsdorf T, Hamann T (2020) Plant cell wall integrity maintenance in model plants and crop speciesrelevant cell wall components and underlying guiding principles. Cell Mol Life Sci 77(11):2049-2077. https://doi.org/10.1007/ s00018-019-03388-8

Hasegawa K, Kamada S, Takehara S, Takeuchi H, Nakamura A, Satoh S, Iwai H (2021) Rice putative pectin methyltransferase gene OsPMT10 is required for maintaining the cell wall properties of pistil transmitting tissues via pectin modification. Plant Cell Physiol (In Press). https://doi.org/10.1093/pcp/pcab078

Henry JS, Lopez RA, Renzaglia KS (2020) Differential localization of cell wall polymers across generations in the placenta of Marchantia polymorpha. J Plant Res 133:911-924

Honta H, Inamura T, Konishi T, Satoh S, Iwai H (2018) UDP-arabinopyranose mutase gene expressions are required for the biosynthesis of the arabinose side chain of both pectin and arabinoxyloglucan, and normal leaf expansion in Nicotiana tabacum. J Plant Res 131:307-317

Inoue H, Fukuoka D, Tatai Y, Kamachi H, Hayatsu M, Ono M, Suzuki S (2012) Properties of lead deposits in cell walls of radish (Raphanus sativus) roots. J Plant Res 126:51-61

Ishida T, Suzuki R, Nakagami S, Kuroha T, Sakamoto S, Nakata MT, Yokoyama R, Kimura S, Mitsuda N, Nishitani K, Sawa S (2020) 
Root-knot nematodes modulate cell walls during root-knot formation in Arabidopsis roots. J Plant Res 133:419-428

Iwai H, Hokura A, Oishi M, Chida H, Ishii T, Sakai S, Satoh S (2006) The gene responsible for borate cross-linking of pectin Rhamnogalacturonan-II is required for plant reproductive tissue development and fertilization. Proc Natl Acad Sci USA 103(44):1659216597. https://doi.org/10.1073/pnas.0605141103

Iwai H, Terao A, Satoh S (2013) Changes in distribution of cell wall polysaccharides in floral and fruit abscission zones during fruit development in tomato (Solanum lycopersicum). J Plant Res 126:427-437

Kotake T, Yamanashi Y, Imaizumi C, Tsumuraya Y (2016) Metabolism of L-arabinose in plants. J Plant Res 129:781-792

Le Gall H, Philippe F, Domon JM, Gillet F, Pelloux J, Rayon C (2015) Cell wall metabolism in response to abiotic stress. Plants (Basel) 4(1):112-166. https://doi.org/10.3390/plants4010112

Nagayama T, Nakamura A, Yamaji N, Satoh S, Furukawa J, Iwai H (2019) Changes in the distribution of pectin in root border cells under aluminum stress. Front Plant Sci 10:1216

Nardi C, Escudero C, Villarreal N, Martínez G, Civello PM (2013) The carbohydrate-binding module of Fragaria $X$ ananassa expansin 2 (CBM-FaExp2) binds to cell wall polysaccharides and decreases cell wall enzyme activities "in vitro." J Plant Res 126:151-159

Saelim L, Akiyoshi N, Tan TT, Ihara A, Yamaguchi M, Hirano K, Matsuoka M, Demura T, Ohtani M (2018) Arabidopsis group IIId ERF proteins positively regulate primary cell wall-type CESA genes. J Plant Res 132:117-129

Scheller HV, Ulvskov P (2010) Hemicelluloses. Annu Rev Plant Biol 61:263-289. https://doi.org/10.1146/annurev-arpla nt-042809-112315

Shinohara N, Kakegawa K, Fukuda H (2015) Monoclonal antibodybased analysis of cell wall remodeling during xylogenesis. J Plant Res 128:975-986

Somerville C, Bauer S, Brininstool G, Facette M, Hamann T, Milne J, Osborne E, Paredez A, Persson S, Raab T,Vorwerk S, Youngs H (2004) Toward a systems approach to understanding plant cell walls. Science 306(5705):2206-2211. https://doi.org/10.1126/ science. 1102765
Takebe N, Nakamura A, Watanabe T, Miyashita A, Satoh S, Iwai H (2020) Cell wall glycine-rich protein2 is involved in tapetal differentiation and pollen maturation. J Plant Res 133:883-895

Takizawa A, Hyodo H, Wada K, Ishii T, Satoh S, Iwai H (2014) Regulatory specialization of xyloglucan (XG) and glucuronoarabinoxylan $(\mathrm{GAX})$ in pericarp cell walls during fruit ripening in tomato (Solanum lycopersicum). PLOS ONE 9:e89871

Tanaka N, Kato M, Tomioka R, Kurata R, Fukao Y, Aoyama T, Maeshima M (2014) Characteristics of a root hair-less line of Arabidopsis thaliana under physiological stresses. J Exp Bot 65:1497-1512

Terao A, Hyodo H, Satoh S (2013) Iwai H (2013) Changes in the distribution of cell wall polysaccharides in early fruit pericarp and ovule, from fruit set to early fruit development, in tomato (Solanum lycopersicum). J Plant Res 126:719-728

Tsuchiya M, Satoh S, Iwai H (2015) Distribution of XTH, expansin, and secondary-wall-related CesA in floral and fruit abscission zones during fruit development in tomato (Solanum lycopersicum). Front Plant Sci 6:323

Uno H, Tanaka-Takada N, Hattori M, Fukuda M, Maeshima M (2019) A cell-wall protein SRPP provides physiological integrity to the Arabidopsis seed. J Plant Res 132:145-154

Yamamoto T, Nakamura A, Iwai H, Ishii T, Ma JF, Yokoyama R, Nishitani K, Satoh S, Furukawa J (2012) Effect of silicon deficiency on secondary cell wall synthesis in rice leaf. J Plant Res 125:771-779

Yokoyama R, Nishitani K (2004) Genomic basis for cell-wall diversity in plants. A comparative approach to gene families in rice and Arabidopsis. Plant Cell Physiol 45:1111-1121

Zhang W, Wu L, Ding Y, Yao X, Wu X, Weng F, Li G, Liu Z, Tang S, Ding C, Wang S (2017) Nitrogen fertilizer application affects lodging resistance by altering secondary cell wall synthesis in japonica rice (Oryza sativa). J Plant Res 130:859-871

Publisher's Note Springer Nature remains neutral with regard to jurisdictional claims in published maps and institutional affiliations. 